Session 3151

\title{
Teaching the Business of Engineering
}

\author{
Harriet S. Cornachione, Michael A. Cornachione \\ Oregon Institute of Technology
}

\section{Introduction}

Typical of most civil engineering programs, the Civil Engineering and Surveying Department at Oregon Institute of Technology (OIT) requires civil engineering majors to take senior-design, or capstone courses. These courses are intended to expose students to engineering problems similar to those they will encounter when they begin their careers. In keeping with traditional educational methodology, the classes generally become part lecture, part problem development, and part final design. The course instructor, in essence, guides students to a successful, technically correct conclusion. Despite these capstone design courses, students frequently have a high degree of anxiety entering the workplace as they still are not sure exactly what will be required of them. Commonly, students express concerns about whether they can meet the demands of their employers, once they are performing outside of the familiar classroom environment.

In the business of engineering, the hierarchy of an office is substantially different than that established at an institution of higher learning. Recent engineering graduates typically are assigned to a design group of engineers headed by a team leader. This team generally has the responsibility for the majority of design work performed on a project. Senior level engineer review and comment on the progress and quality of the work, but most of the design is in the hands of the engineering team. New engineers-in-training may find they have what appears to be far more responsibility than they either want or feel they are capable of handling. Problems are no longer scripted with a single correct answer. In fact, there frequently is no clear right or wrong answer. Engineers must create a solution based on various parameters including sound engineering practices, time and budget constraints, and capabilities and best judgment of the engineering design team.

To facilitate the successful transition from "engineering student" to "engineer," a course was designed at OIT to simulate the workings of an engineering consulting firm. The specific course was a capstone design course in environmental engineering, but could be applied to almost any field in civil engineering. Students are told at the initial class meeting that new material will be not be presented by the faculty. The course scenario is then described to them.

Students are new, junior engineers in a consulting firm with the faculty acting as senior engineers for the firm. Faculty members are no longer to be considered teachers, but rather a part of the design team and process. Students are not working to satisfy their professors, but rather are required to perform to the standards of a professional engineer, meeting the expectations of a real client. 


\section{The Consulting Firm}

\section{Overview of Format \& Requirements}

Once the scenario is set for the students, the business environment is emplaced in the classroom and the consulting firm's operating format is presented to the "new hires". As junior engineers the students are required to work in teams to complete a specific design project. Each group is given several Request for Proposal's (RFP's) from actual proposed projects in and around the Klamath Basin region. Each team is given the opportunity to select a project that they determine best meets the combined qualifications and interests of their team. Their initial charge is to prepare a proposal in response to the RFP of their choice. Upon completion and presentation of their proposal, teams are required to complete their design projects.

In addition to their own projects, individual junior engineers are required to develop a unique expertise or knowledge on a subject relevant to environmental engineering. They must present information to the entire class to facilitate the transfer of technical knowledge within a consulting firm. While each student selects an individual topic, all design groups could then use reference material supplied by the student or contact that student directly if their team needed information on that topic. The purpose of this requirement is to simulate a common means in industry of distributing information gained from short courses, workshops and conferences attended wherein attending engineers give an overview presentation of the knowledge gained from their meeting to their co-workers, maximizing the benefit of the firm's educational funds.

\section{Engineering Team Selection}

Students are placed into groups or design teams (of 3-4 students each) by the faculty, much as they would be in industry. Groups are selected in an attempt to balance the competencies of each team. Technical competencies are not the only consideration in the selection of the groups. To be an effective team, recognition is given to the need for each group to contain a variety of skills including written and oral communication, management and marketing techniques as well as technical abilities. During the progress of the project, students could begin to appreciate and better utilize the skills of all the members on the team. More importantly, students see that technical competence is not the only valued trait in business. Individuals who can communicate information effectively to a client are as, if not more, important than the lead design engineer just as it is in industry.

\section{Request for Proposal}

Engineering students, typically, do not envision the professional engineer as someone who has to market a service or needs to seek projects. In part, this is a result of the tendency in engineering classes to review the contractor-engineer relationship while overlooking the client-engineer relationship. Engineering firms usually obtain work either through referrals or through a competitive process that begins with the Request for Proposal (RFP). To address that issue, the assigned design teams were given a number of RFP's to review. 
The RFP's are obtained through discussions with local agencies and private businesses to give the groups a range of projects to select. This gives design groups some flexibility to assess their internal capabilitites and match them with the projects. Teams then select a project that they feel competent in pursuing and prepare written and oral proposals for that project. Past projects include:

- Non-Point Source Pollution Study (NPSPS): City of Klamath Falls Storm Drain System

- Hydrogeologic Site Assessment for Proposed Klamath County Landfill Expansion

- Wetland Restoration of the Caledonia Marsh Area, Upper Klamath Lake

To further emulate a "real world" situation, different teams are permitted to submit proposals for the same project and receive the award based on a competitive process of evaluation of the engineering design components of their proposal. This option has yet to be exercised since the groups ultimately have selected separate projects, avoiding any competition. In part this may reflect a rapid recognition by the students that the time constraints involved in preparation of the proposal can be significant and they are unwilling to risk that time and effort on a possible lost bid.

The teams are given a short (two-week) time frame to prepare their proposals, not unlike the urgency frequently required in real consulting firms. During this two-week period, teams could also make field visits and have discussions with agency representatives involved in the projects. Senior engineers facilitate the field visits and are available for consultation regarding appropriate sources of information and data to develop the proposals.

\section{Proposal Requirements}

The competitive process to obtain work, especially government projects, begins with a proposal. Consulting firms are required to present a written proposal, including their firm's qualifications for the project. A committee review of written proposals develops a short list of firms that are then required to make a more formal oral presentation from which the bid awardee is selected. The class was designed to simulate this competitive process. Design groups had to prepare professional quality proposals to obtain the work. Design teams were made aware that their proposal and final project would be reviewed by the agency requesting the project. To assist in developing the written proposals the teams were given various examples of actual proposals presented by consulting firms. Individual RFP's also had specific requirements for the proposals. Oral presentations were left open to the discretion of each team. Teams were told to clearly state project goals and expected outcomes, develop an organizational chart for their team, and include a time line for meeting the stated goals.

In the development of the proposal, the teams must list their capabilities and expertise, including resumes and team organizational structure. Initially the students balk at this aspect, arguing that they have no real qualifications. Prompting teams to list the kinds of problems they think they could solve or have solved in their studies or on the job leads teams to formulate a list of 
qualifications. Teams are usually surprised but impressed by their own qualifications when these are actually documented. It quickly becomes evident that they do in fact have some specialized skills and knowledge that will not only be important to the team, but of value to a client.

The proposal also allows teams to look at the project as a whole. They have to set the goals and scope of the project based upon the time allotted for completion of the project. These goals and standards, usually established by an instructor, are now being developed by the student teams, just as they will soon be doing for an employer. Another benefit of the proposal is that the teams now have self-imposed time constraints for project goals. During the project phase, the guidelines set forth in the proposal help the teams to stay on task and focused, rather than be deterred by intriguing but tangential issues. In retrospect it is evident that the development of the proposal is a key ingredient in producing a successful project.

\section{The Design Phase}

Upon successful completion of the proposal, teams begin work on their projects. The project teams are required to meet with the senior engineers, the faculty, for 30 minutes each week. These meetings are used to discuss the previous weeks' accomplishments or setbacks, reaffirm tasks for the upcoming week, and to ensure schedules are being met.

Team members generally find that they do far more research and use creative and critical thinking to solve problems and develop their design solutions than relying on the use of familiar equations to provide the solutions. For example, the wetlands project required the team to design inlet and outlet structures for the area, as part of the problem. Sizing a structure based on projected flows is a relatively easy problem to solve. The harder problem is to decide which type of structure would best suite the particular project constraints and conditions, and best meet the needs of the client.

Research efforts often pushed the limits of the field of environmental engineering. For instance, team members of the wetlands project met with scientists from the local U.S.F.W. Ecosystem Restoration Office. This was an enlightening experience for the trained engineer. Each scientist had specific concerns and priorities in the development of wetlands depending on their expertise and particular charge. Some wanted to maximize water quality contributions of the wetland while others were more interested in improving habitat for various flora or fauna. The team members could get little or no specific design criteria from the scientists, only recommendations on what they wanted to accomplish. This group of scientists, however, was responsible, in large part, for evaluating the success of the overall wetlands development being performed by the team's client as specified by various government permits. The engineering team had to create a unique design for the project without the familiar support of standard engineering formulas or equations. A further realization was that any design would probably be unsatisfactory to some party was an enlightening, if not comfortable, experience for the [student] teams. Teams clearly learned the reality of balancing the needs of their client and the expectations of government agencies and of meeting permit regulations. 


\section{Final Reports}

The engineering teams are responsible for preparation of a final design report and oral presentation of their project. For most projects, the team is able to report directly to the client, as well as the senior engineers and their fellow engineering design teams. Response from those government agencies and industries who have participated has been quite favorable. Teams are encouraged to present portions of the final report at each weekly meeting with the senior engineers. Initially hesitant to document any work, or even begin writing until the entire engineering project is completed, teams soon find that there are many aspects of the engineering design process that must be documented, including their approach in scoping and limiting the problem. Any choices between technically viable options to solve any portion of the design phase must be clearly, if concisely, stated in their report (i.e. the wetlands inlet and outlet structures selection discussed earlier). Introductory segments and format for the reports are frequently defined by the proposals and can be prepared early in the project. Base maps, AutoCAD drawings and some of the supporting data obtained for the project should be prepared as soon as possible. Teams gain confidence in their design abilities and strengthen their communication skills during this phase of the project. The presentation segment is invaluable for the experience it provides the student in explaining his/her engineering problem-solving approach to a critical audience who are present with questions.

\section{Conclusions}

Student response to the experience has been very favorable. The objective of the course is to increase student awareness of the practice/business of engineering and assist them in developing skills to facilitate the transition from school to the workplace, as well as to help them integrate their engineering knowledge into engineering problem solving. Specific gains reported by students are not surprising, but indicate that the course is meeting these objectives. As all practicing engineers know, engineers are required to do more than sit and solve problems using textbooks, stock equations and models. Students were not previously aware of the amount of time spent in what they perceived as non-engineering tasks. These include the proposal preparation and the research required to obtain information on their specific problems. Students also had to make efficient use of their time, and, despite the support of a team could not afford to procrastinate on their project tasks such as they might have on traditional schoolwork. They also had to rely on the abilities of others in order to complete the project within the time permitted for the course. Sometimes this meant accepting a product that they might have improved upon if given more project time, or the opportunity to perform the work on their own.

The problems the engineering students had in communicating effectively with the scientists were interesting dilemmas. To help bridge engineering with the sciences one option that is being explored is to expand the class to include students from the Applied Environmental Science program. It would be beneficial to both groups of students to have an integrated design project with both engineers and scientist involved as a team. Another idea under consideration is to further integrate this class with a Technical Communications faculty and/or course assisting in the proposal and report preparation. 
The actual running of the class is not particularly time-consuming. The effort, however, comes in the development of the projects and the interaction with local agencies and businesses. Local agencies and companies who have helped develop projects have continued supporting the class. Once this relationship is established future projects become easier to formulate. One company, involved with the restoration project, actually hired a graduating senior to continue work on that effort. The far more difficult task for the faculty was in staying in the role of senior engineer, acting as an advisor and allowing the team to move toward their own solution.

HARRIET S. CORNACHIONE is an Assistant Professor in the Department of Civil Engineering and Surveying at the Oregon Institute of Technology. Her teaching areas include Geological and Environmental Engineering. Harriet has also worked extensively in the mining industry and with oil and gas companies.

MICHAEL A. CORNACHIONE is an Associate Professor in the Department of Civil Engineering and Surveying at the Oregon Institute of Technology. His teaching areas include Geotechnical and Environmental Engineering. Michael has worked as a Geotechnical Consultant in Saudia Arabia, Alaska, and Oregon. 